\title{
Factors Hindering the Adoption of E-Marketing among Cable Manufacturers in Zambia, Based on Technology Acceptance Model (TAM)
}

\author{
Norbert Mooya ${ }^{{ }^{*}}$, Jackson Phiri ${ }^{2}$ \\ ${ }^{1}$ Graduate School of Business, University of Zambia, Lusaka, Zambia \\ ${ }^{2}$ Department of Computer Sciences, School of Natural Sciences, University of Zambia, Lusaka, Zambia \\ Email: ^Norbert.mooya@gmail.com, Jackson.phiri@cs.unza.zm
}

How to cite this paper: Mooya, N., \& Phiri, J. (2021). Factors Hindering the Adoption of E-Marketing among Cable Manufacturers in Zambia, Based on Technology Acceptance Model (TAM). Technology and Investment, 12, 51-65. https://doi.org/10.4236/ti.2021.122004

Received: December 10, 2020

Accepted: March 2, 2021

Published: March 5, 2021

Copyright () 2021 by author(s) and ScientificResearch Publishing Inc.

This work is licensed under the CreativeCommons Attribution International

License (CC BY 4.0).

http://creativecommons.org/licenses/by/4.0/

\begin{abstract}
The study was looking at establishing factors that are hindering the adoption of electronic marketing among cable manufacturers in Zambia based on the Technology Acceptance Model (TAM). The study first looked at the major challenges faced by cable manufacturing companies in developing countries in the adoption of e-commerce in marketing their products. The study then proposed a model through a web-based e-commerce web portal that could be adopted in order to address the challenges identified in the study. The study was based on three cable manufacturing companies. The three companies had a total population of 115 respondents which was used in our study. These were from the various departments (Marketing, IT and Management) within their respective organizations. Both qualitative and quantitative data was collected from respondents using a structured questionnaire. The questionnaire was generated based on the TAM conceptual model. The response rate was 47\% giving 51 questionnaire responses from the three companies. The Chi-Square test of independence was used to analyze the data using SPSS software. The results showed that age has an influence on the perceived usefulness of technology. The test had an observed $P$-Value of 0.024 against the significance level of 0.05 .The results further showed that frequent use of the internet has an influence on perceived ease of use of technology. An observed $P$-Value of 0.014 was recorded against the significant level of 0.05 . The Chi Square test again recorded an observed $P$-Value of 0.03 against the significance level of 0.05 , revealing that Internet knowledge has an influence on perceived security of E-marketing. It was therefore, concluded that level of education has no influence on perceived security of E-Marketing. Based on these results, an e-commerce prototype was developed as a web portal to help address the challenges of technology adoption in cable marketing by the three
\end{abstract}


companies in the study.

\section{Keywords}

E-Marketing, Adoption, Technology Acceptance Model (TAM), Cable

Manufacturing Companies

\section{Introduction}

Kotler and Armstrong (2008) stated that the Internet had given marketers a whole new way to create value for customers and built customer relationships. E-marketing by definition is the Electronic Marketing of products and services over the internet (Khan, n.d.). E-Marketing is sometimes called Digital Marketing. E-Marketing presents itself with benefits to business houses which include a low-cost way to reach billions of people worldwide as well as creating a better relationship with clients. Made popular in the 1990s, twenty years after its invention, E-marketing is spreading all over the world, with a volume estimated at USD 1500 billion in 2014, according to E-Marketer 1 (Ducass \& Kwadjane, 2015). Despite such developments in Information Communication Technology (ICT), the Middle East and Africa still find themselves in a marginal position. According to the United Nations Conference on Trade and Development (UNCTAD), Africa remains the region with the lowest e-commerce penetration, with about 2.2\% of global Business 2 Consumer e-commerce in 2013. Despite notable benefits technology presents, it has also come with its own challenges in adopting it. Switching to technological applications means that users have to abandon their conventional methods of doing things. This sometimes leads to resistance to adopting technology.

\section{Literature Review}

The revolution in information technology (IT) and communications has changed the way people conduct business today. This has been catalysed by the unprecedented progress in web technologies that lead to the development of many electronic applications (AvciYucel \& Gulhahar, 2013). In recent years, an increased number of businesses have been using the Internet and other electronic media in conducting their marketing efforts, giving the chance for Electronic Marketing (as a new marketing phenomenon and philosophy) to grow in a very dramatic and dynamic way (El-Gohary, 2014). E-marketing has been defined in many ways by different scholars worldwide. EL-Gohary (2014) defined Electronic Marketing (E-Marketing) as a new philosophy and a modern business practice involved with the marketing of goods, services, information and ideas via the Internet and other electronic means. Onyeocha and Chinonso (2015) also added their contribution by defining E-Marketing or electronic marketing as the application of marketing principles and techniques via electronic media and 
more specifically the Internet. They further stated that the terms E-Marketing, Internet marketing and online marketing, are frequently interchanged, and can often be considered synonymous. Scholars called Andreki \& Yazidanfard (2014) defined E-Marketing the art and process of utilizing existing and emerging communication and data networks to impart personalized and uninterrupted communication between the firm and its customers and to provide value above traditional networks.

E-Marketing itself presents a number of benefits to the company utilizing it, among them the ability meets the needs of niche markets and typically have less overhead than traditional face to face marketing (Bolos, Idemundia, Mai, Risinghani, \& Smith, 2016). E-marketing also provides businesses with access to mass markets at an affordable price and allows them to undertake personalised sales techniques in order to satisfy such markets. It further allows companies find new markets for their products and compete with little or reasonable investments. Despite the noted benefits Onyeocha \& Chinonso (2015) argued that there are also drawbacks of adopting E-Marketing. For example, before you get started with your e-marketing, it is very important to have some skills and know-how in order to run an e-campaign effectively. If not, you run the risk of wasting your valuable resources with a poor campaign.

According the Ponos London report (2010), the biggest challenge facing potential E-Marketing adopters in Zambia is the high cost of equipment and broadband services. ICT equipment is already expensive for the citizens of a country with a per capita GNP which only just exceeds the cost of a single personal computer. The cost of PCs and peripherals such as modems is pushed up further by high rates of taxation. The Ponos London report further highlighted that poor access to international infrastructure, leading to high broadband prices, is the biggest challenge facing communications service providers in Zambia.

\section{Electronic Marketing Adoption Factors}

Technology adoption is one of the mature areas of research in information systems (Sharma \& Mishra, 2014). According to Doradulo (2016), Technology Acceptance Model (TAM) is becoming more and more popular in helping understand the relationship between a human being and technology through the two variables namely perceived usefulness and perceived ease of use. Several researchers have put across various theories explaining reasons why users accept or reject the use of technology. Some of the various theories developed in this vein are highlighted below.

The first theory to be explained is Theory of Reasoned Action (Fishbein \& Ajzen, 1980). Theory of Reasoned Action (TRA) has its roots in social psychology setting. The theory proposes three general constructs, namely "behavioural intention (BI), attitude (A), and subjective norm (SN)". Theory of reasoned action can be interpreted that behavioural intention is the summa- 
tion of attitude and subjective norms. The other theory which has a psychological aspect as to why human beings behave in certain way called Bandura's Social Cognitive Theory. Social cognitive theory defines learning as an internal mental process that may or may not be reflected in immediate behavioural change (Bandura, 1986). Here Bandura argues that human beings learn by observing others. Theory of Planned Behaviour (TPB) (Ajzen, 1991) is another one worth discussing. According to Ajzen (1991) the TPB is a theory designed to foresee and explain the human behaviour in specific contexts, for example, in information systems. The perceived behavioural control reflects the belief about the access to the resources and to the necessary opportunities to perform determined behaviour (Oliveira, 2006). As general rule, the stronger the intention to get involved in an behaviour, the more probable should be its performance.

Unified Theory of Acceptance and Use of Technology (UTAUT) (Venkatesh, et al., 2003) is yet another theory of technology acceptance. The theory was established on four theoretical constructs representing determinants of Use Behaviour or the Intention to Use, which play essential roles as surrogates of Technology Acceptance. These constructs are: Performance Expectancy, Effort Expectancy, Social Influence, and Facilitating Conditions. In addition to these variables the theory considers also Moderating Factors which moderate the relations between various constructs and Intention to Use. The Moderators are Gender, Age, Experience, and Voluntariness of use.

\section{Technology Acceptance Model (Davis 1989)}

Technology Adoption Model (TAM) has been widely used in technology adoption studies. The strength of the model lies in its simplicity as it has only two constructs, namely, "perceived usefulness" and "perceived ease of use" for predicting extent of adoption of new technologies at individual level. Figure 1 below shows this depiction as illustrated by Fred Davis in 1989.

Sharma \& Mishra asserted that Technology Acceptance model was subjected to a test in Canada and findings revealed that that perceived usefulness is a stronger factor than perceived ease of use that drives technology adoption. This made TAM to become well-established as a robust, powerful, and parsimonious model for predicting user acceptance.

\section{Methodology and Conceptual framework Development}

\subsection{Conceptual Framework Development and Hypothesis}

This research paper adopted Technology Acceptance Model in order to identify factors leading to the acceptance or rejection of E-Marketing. The conceptual model developed is summarized by Figure 2 below.

\section{Hypothesis}

In line with above, the following hypotheses were developed in this study;

H1: Age has an influence on Perceived Usefulness. 


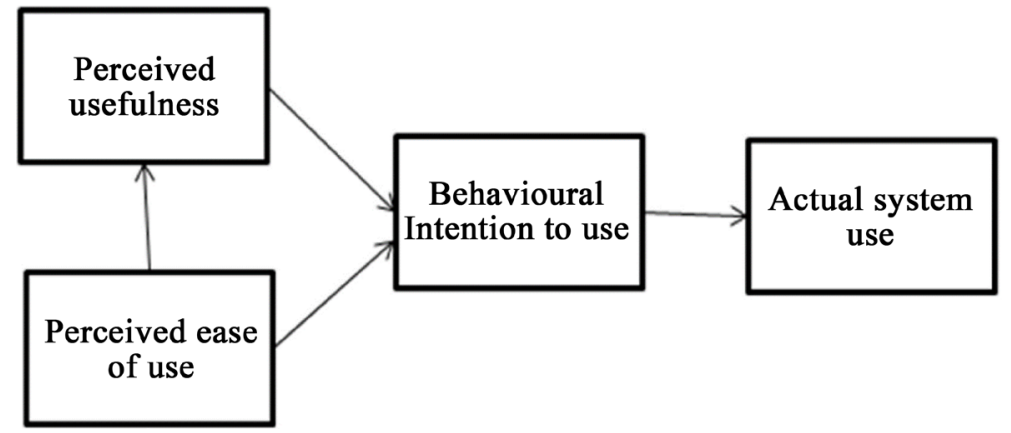

Figure 1. Technology Acceptance Model (TAM) (Davis, 1989).

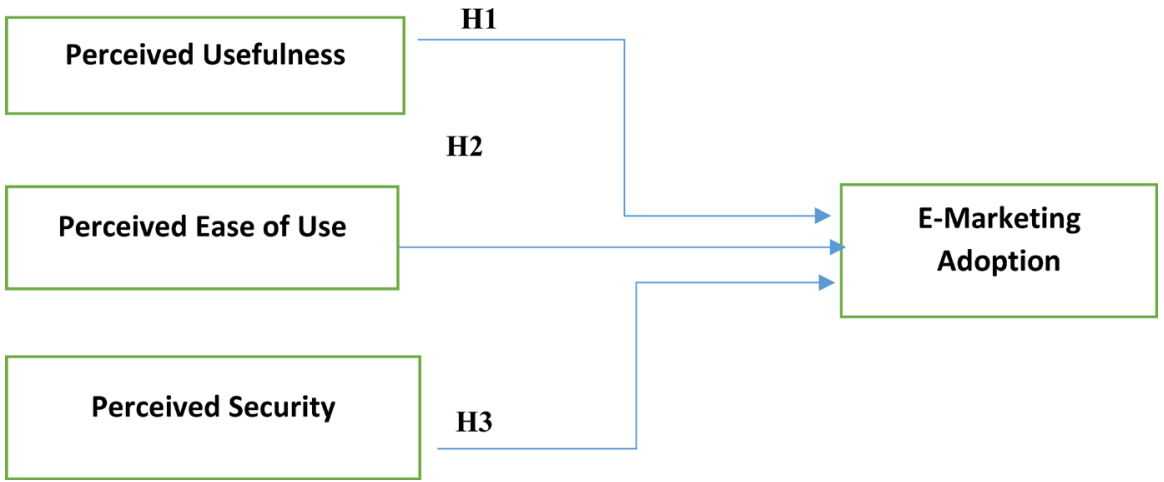

Figure 2.Adopted conceptual frame work for E-Marketing. Source: (Davis, 1989).

H2: Frequency of internet use has an influence on Perceived Ease of Use.

H3: Internet Knowledge has an influence on Perceived Security.

H4: Level of Education has an influence on Perceived Security.

\subsection{Research Design, Target Population, Sample Size Determination and Data Processing Procedure}

The adopted research design was quantitative research. Precedence was also set by similar studies which include: Olotewo (2017), Sahli (2015), Akrimi \& Khemakhem (2012), Soneka \& Phiri (2019), Mwiya et al. (2017), Daka \& Phiri (2019), Sakala \& Phiri (2019) and many others.However, descriptive statistics was used to explain the qualitative aspects of the data been analysed. The population of attention for this study was all cable manufacturing companies in Zambia. The study conveniently sampled 3 cable manufacturing companies (Zamefa, Neelkanth and Zalco). From these companies, survey respondents were randomly selected from the various departments (marketing, IT and Management) within their respective organizations. The sample size was determined using Taro Yamane formula. The formula is given by $n=N / 1+N\left(\mathrm{e}^{2}\right)$, where; $\mathrm{n}$; is the sample size, $\mathrm{N}$ : is the Population of the target group ande' ${ }^{2}$ Margin of error. In the researcher's situation, ZAMEFA had 60 people of interest while NEEKANTH Cables had 30 and ZALCO had 25 members. The total population was 115 people. Since the population was relatively small, we used the whole population in our study. We distributed 115questionnaires. However, only 51 came back. This 
represented $44 \%$ response rate. The questionnaire was designed based on the conceptual model in Figure 2. The collection of data was done through primary sources. Primary data was obtained from respondents through self-administered questionnaires. The validity and reliability of the questionnaires were achieved by having well laid and clear questions and also by performing a pilot test before initial administering. Both descriptive and inference statistics were used to analyze the data. The Chi-Square test of independence was used to determine the significant relationship between two nominal (categorical) data in the hypothesis generated from Figure 2.

\subsection{System Automation, Use Case Diagram and System Functionality}

An E-Commerce system called ZAMEFA E-Commerce was developed. Open-source tools or programs were used to develop this system. The Zamefa E-Commerce system was developed using Wamp Server, Maria database, PHP scripting language and Apache Web Server which was used to host the E-commerce web application system. Figure 3 below depicts the steps involved when logging in to ZAMEFA E-Commerce System developed in this research.

Figure 4 is a snap shot the home page of the Zamefa E-Commerce system developed while Figure 5 is a snipping picture of the logging in home page.

\section{Research Results}

\section{Socio-demographic characteristics of respondents}

The figure (Figure 6) shows that majority of the respondents were aged between 21-30 (35.3\% of sample), the age groups (Below 20), (31 - 40), (41 - 50) and (51 - 60), respectively accounted for $2 \%, 33.3 \%, 23.5 \%$ and $5.9 \%$ of our sample. This is also depicted in the bar chart (Figure 10).

\section{Gender distribution of respondents}

Figure 7 below gives the percentages and frequencies of the gender variable.
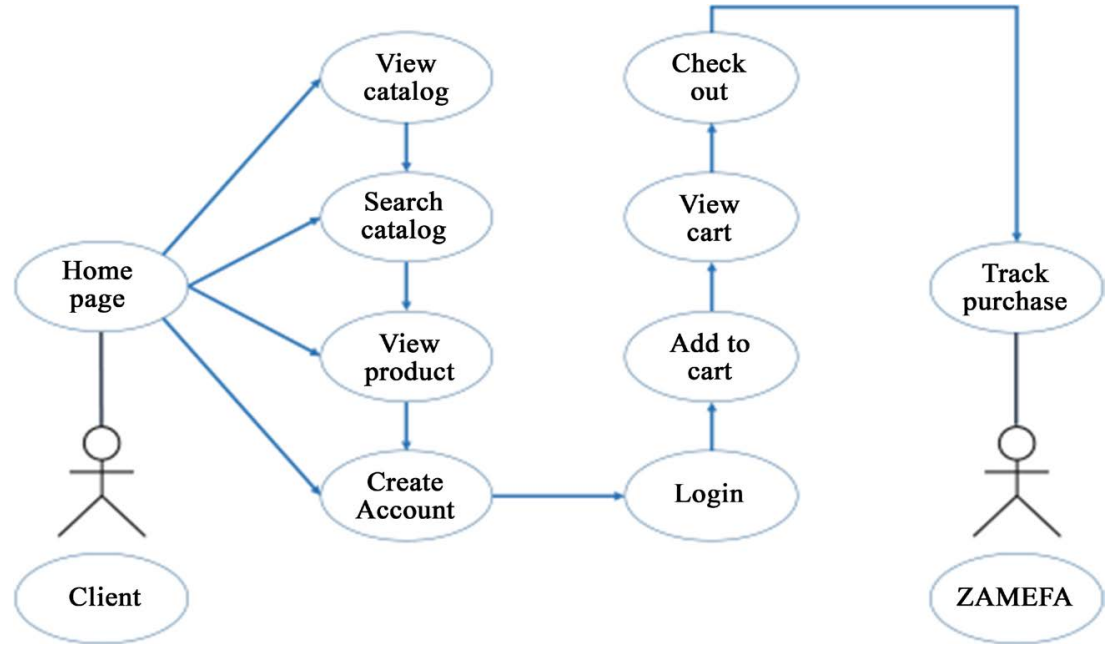

Figure 3. ZAMEFA e-commerce use case diagram. 


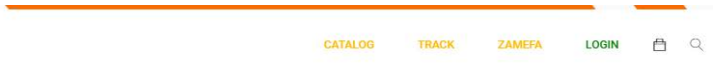

\section{ZAMEFA QCOMMERCE}

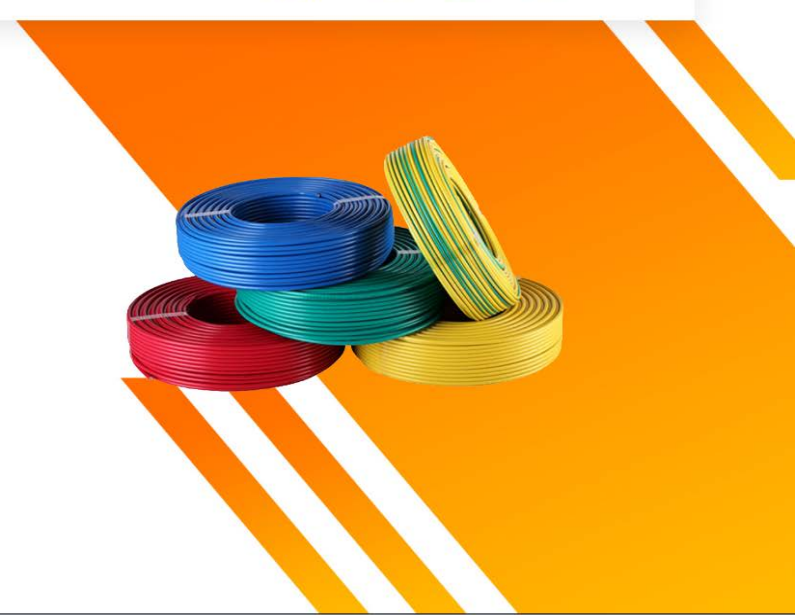

Figure 4. System home page.
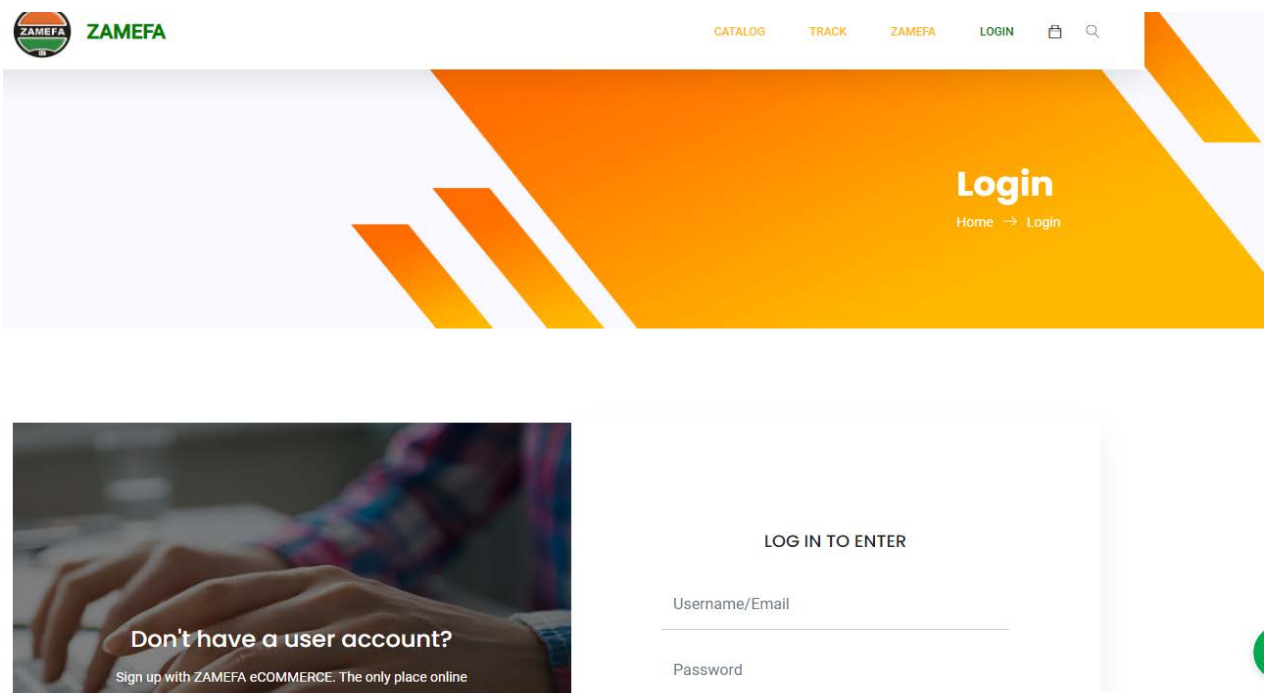

LOG IN TO ENTER

Figure 5. Login homepage.

SAMPLE DISTRIBUTION BY AGE GROUP

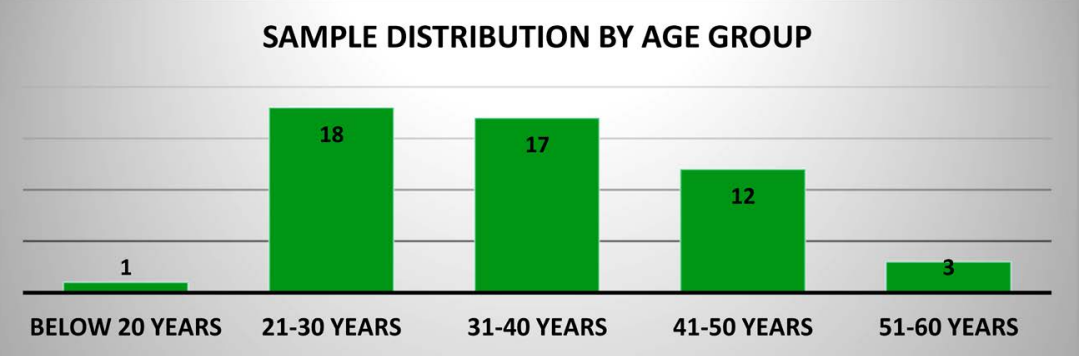

Figure 6. Study sample by age.

The gender composition of the sample was 36 males (representing $71 \%$ of the sample respondents) 15 females ( $29 \%$ of the sample respondents).

Education background of respondents

Figure 8 summarized education background frequencies and percentages of 


\section{GENDER COMPOSITION OF THE SAMPLE}

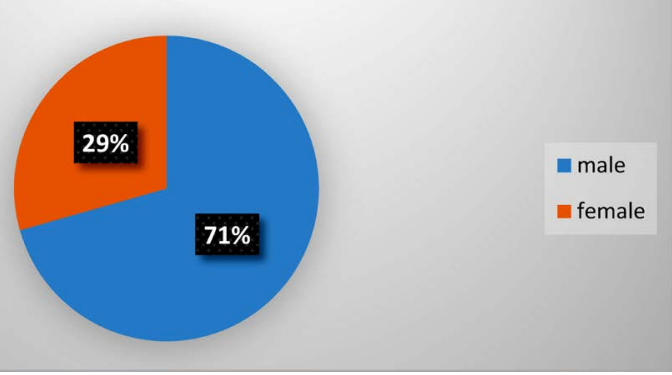

Figure 7. Gender composition of sample.

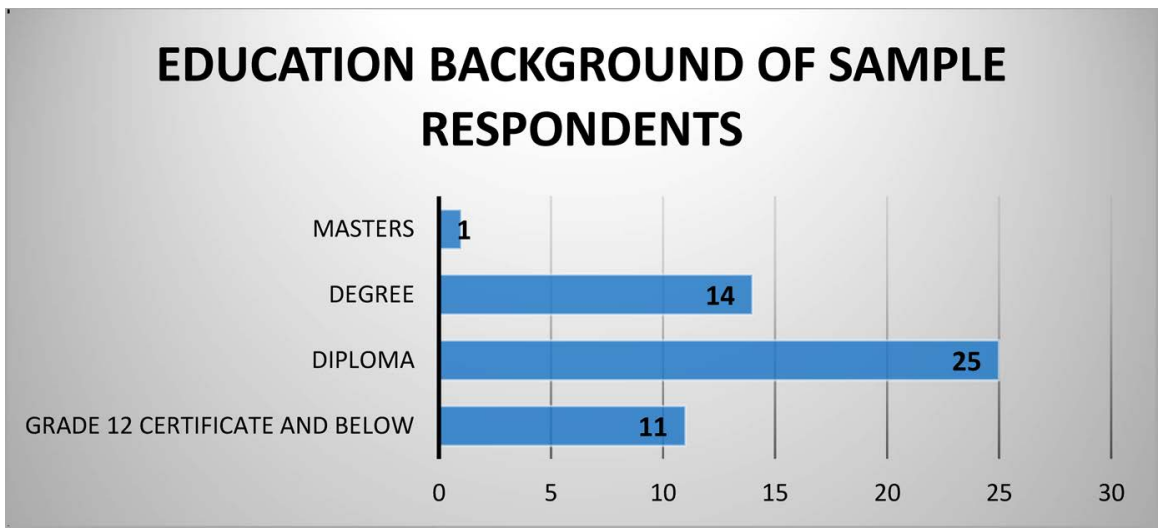

Figure 8. Education background of respondents

sample respondents. Survey results indicated that $21.6 \%$ of the respondents were educated up to grade 12 level, while the majority (49\%) were educated up to diploma level. The remaining $27.5 \%$ and $2 \%$ were educated up to Degree and Masters Level respectively.

\subsection{Results Based on the Perspective and Technology Acceptance Model}

The Chi-Square test of independence is used to determine if there is a significant relationship between two nominal (categorical) variables. The frequency of each category for one nominal variable is compared across the categories of the second nominal variable. This research adopted Chi-Square as the base of analysis. Hypothesis testing was also carried out using $P$-Value approach.

Dahiru (2008) defined $P$-Value as the probability under the assumption of no effect or no difference, of obtaining a result equal to or more extreme than what was actually observed. The P stands for probability and measures how likely it is that any observed difference between groups is due to chance. Since $P$ is a probability, it can take any value between 0 and 1 . The rule of thumb states that if the $P$-Value is less than the level of significance i.e. the standard 0.05 , then it has strong evidence against the null hypothesis. In this research, the level of significance used was the tradition 0.05 . 


\subsubsection{Age VS Perceived Usefulness}

\section{- E-marketing and company productivity}

As shown in the graph below, across the age groups the frequencies are higher for the "agree" and "strongly agree" categories. These results seem to suggest that age seems to have an influence on perceived usefulness of E-marketing with respect to perceived increase in company productivity.

\section{Hypothesis 1:}

H0: Age has no influence on perceived usefulness of E-marketing (company productivity)

$\mathrm{H1}$ : Age has an influence on perceived usefulness of E-marketing (company productivity)

\section{Pearson Chi-Square test statistic 23.452.718 ( $p$-value $=0.024)$}

Figure 9 depicts the relationship between Age and Perceived Usefulness. According to the Chi-Square test results in Table 1 below, the observed $P$-value $(0.024)$ is less than the significance level of 0.05 , hence the test is significant and we conclude there is evidence to suggest, Age has an influence on perceived usefulness of E-marketing.

\subsubsection{E-Marketing and Company Performance}

Figure 10 below is another depiction of age and perceived usefulness factor

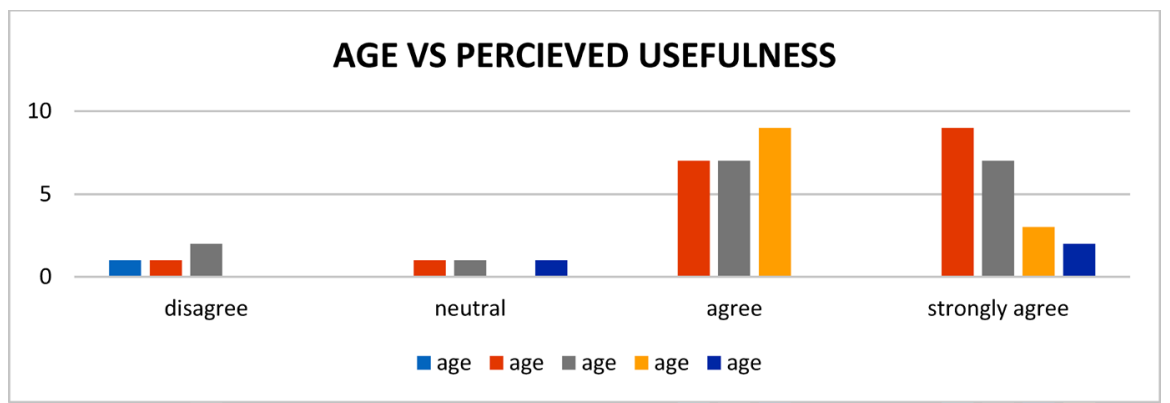

Figure 9. Age vs perceived usefulness.

Table 1.Chi-Square tests results for age vs perceived usefulness.

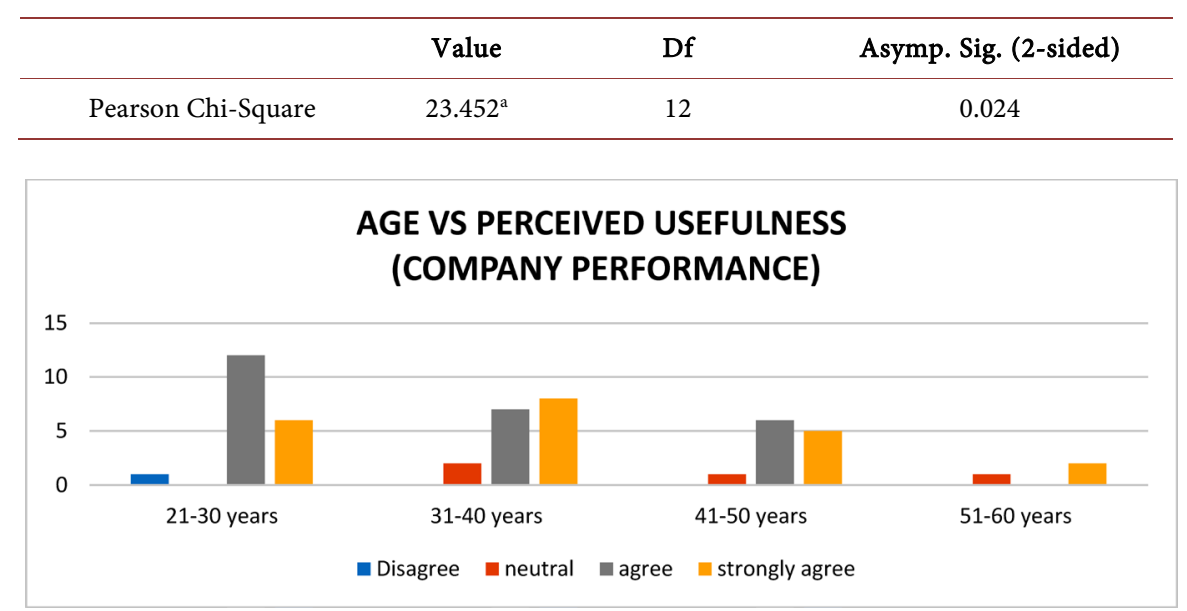

Figure 10. Age vs perceived usefulness (company performance). 
(E-marketing would increase company performance). Like the above case, across the age groups the frequencies are higher for the "agree" and "strongly agree" categories. These results seem to suggest that age seems to have an influence on perceived usefulness of E-marketing with respect to perceived increase in company performance.

\section{Statement of hypothesis 1:}

H0: Age has no influence on perceived usefulness of E-marketing (company performance)

H1: Age has an influence on perceived usefulness of E-marketing (company performance)

Pearson Chi-Square test statistic $58.930(p$-value $=0.000)$

According to the Chi-Square test results shown in Table 2, the observed $P$-value $(0.000)$ is less than the significance level of 0.05 , hence the test is significant and we conclude there is evidence to suggest, Age has an influence on perceived usefulness of E-marketing.

\subsubsection{Frequency of Internet Use VS Perceived Ease of Use}

As indicated in Figure 11 below, the majority of respondents who spent at least three hours a day on the internet agreed that E-marketing would be User friendly. The interest at hand was to test if perception (of user friendliness) was influenced by how much time one spends on the internet daily.

\section{Statement of hypothesis 2:}

H0: Frequency of internet use has no influence on perceived ease of use of E-marketing

$\mathrm{H1}$ : Frequency of internet use has influence on perceived ease of use of E-marketing.

Conclusion: According to the Chi-Square test result shown in Table 3 below, the observed $P$-value (0.014) is less than the significance level of 0.05 , hence the test is significant and we reject the null hypothesis and conclude there is evidence

Table 2. Chi-Square tests results for age vs. perceived usefulness (company performance).

\begin{tabular}{cccc}
\hline & Value & Df & Asymp. Sig. (2-sided) \\
\hline Pearson Chi-Square & 58.930 & 12 & 0.000 \\
\hline
\end{tabular}

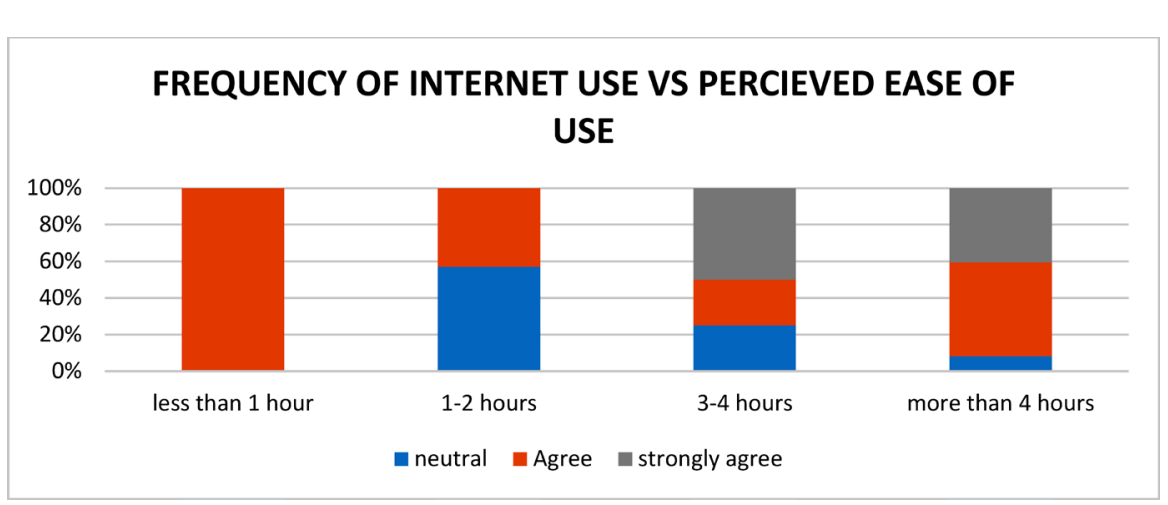

Figure 11. Frequency of internet use. 
to suggest, Frequency of internet use has influence on perceived ease of use of E-marketing.

\subsubsection{Internet Knowledge VS Perceived Security}

The relationship between respondents' knowledge of the internet and the perceived security of E-marketing is Cleary indicated in Figure 12 below. The figure shows that, the responses were varied with a vast majority having a "neutral" view. Thus we subjected this information to a Chi square test of independence in order to establish if perception (of security) is influenced by how much knowledge one has of the internet.

\section{Statement of hypothesis 3:}

$\mathrm{H} 0$ : internet knowledge has no influence on perceived security of E-marketing $\mathrm{H} 1$ : internet knowledge has an influence on perceived security of E-marketing

Conclusion: According to the Chi-Square test indicated in Table 4 below, the observed $P$-value (0.032) is less than the significance level of 0.05 , hence the test is significant and we reject the null hypothesis and conclude there is evidence to suggest, internet knowledge has an influence on perceived security of E-marketing.

\subsubsection{Level of Education VS Perceived Security}

Figure 13 below shows education background versus perceived security of E-marketing. As in the previous case, the results are varied across the different education categories with a vast majority having a "neutral" view. This relationship is subjected to the test below.

\section{Statement of hypothesis 4:}

H0: education has no influence on perceived security of E-marketing.

$\mathrm{H} 1$ : education has an influence on perceived security of E-marketing.

Table 3. Chi-Square tests results for frequency of internet use vs. perceived ease of use.

\begin{tabular}{cccc}
\hline & Value & Df & Asymp. Sig. (2-sided) \\
\hline Pearson Chi-Square & $15.994^{\mathrm{a}}$ & 6 & 0.014 \\
\hline
\end{tabular}

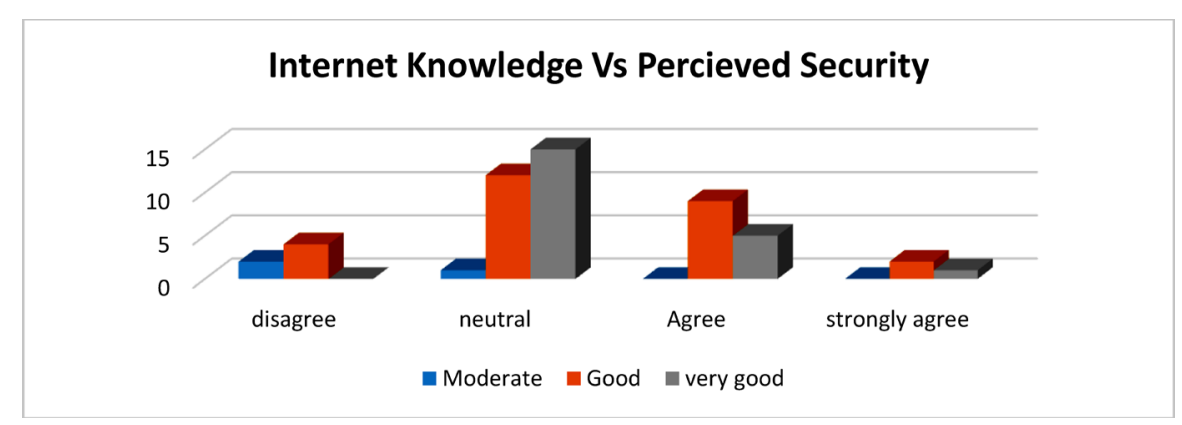

Figure 12. Internet knowledge vs perceived security.

Table 4. Chi-Square tests results: internet knowledge vs. perceived security.

\begin{tabular}{cccc}
\hline & Value & Df & Asymp. Sig. (2-sided) \\
\hline Pearson Chi-Square & $13.800^{\mathrm{a}}$ & 6 & 0.032 \\
\hline
\end{tabular}




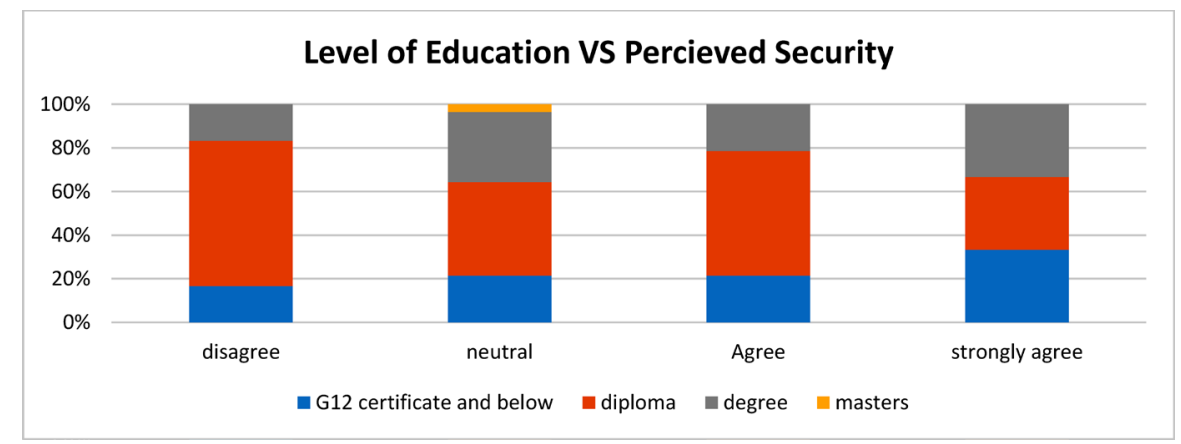

Figure 13. Level of education vs perceived security.

Table 5. Chi-Square tests results: level of education vs. perceived security.

\begin{tabular}{cccc}
\hline & Value & df & Asymp. Sig. (2-sided) \\
\hline Pearson Chi-Square & $2.720^{\mathrm{a}}$ & 9 & 0.974 \\
\hline
\end{tabular}

Conclusion: According to the Chi-Square test highlighted in Table 5 above, the observed $P$-value (0.974) is greater than the significance level of 0.05 , hence the test is insignificant and we fail to reject the null hypothesis and conclude, education has no influence on perceived security of E-marketing.

\section{Conclusion}

The research questions to be answered were:

(i) What are the factors hindering the adoption of an E-Marketing among cable manufacturing companies in Zambia?

(ii) How can an E-Marketing Model Framework and prototype be developed in order to address these challenges in (i)?

In order to answer the "What" question, Chi-Square test of independence was used to determine if there was a significant relationship between two nominal (categorical) variables. Hypothesis testing was also carried out using $P$-Value approach. The findings of the research revealed that age had an influence on perceived usefulness, which was one of the adoption factors of technology according to the Technology Acceptance Model. The observed $P$-Value according to the Chi-Square test conducted was 0.024 . This value is less than the significance level of 0.05 , hence the test was significant and proved that there was evidence to suggest age really had an influence on perceived usefulness of E-marketing.

Furthermore, the findings of the research revealed that frequency of internet use had an influence on perceived ease of use of $\mathrm{E}$ marketing. The $P$-Value recorded according to Pearson's Chi-Square test conducted was 0.014 , which was less than the significance level of 0.05 . Therefore, the test was significant and a conclusion that frequency of internet use had influence on perceived ease of use of E-marketing was made. Another test conducted showed strong evidence to conclude that internet knowledge had an influence on perceived security of E-Marketing. Pearson's Chi-Square test conducted yielded a $P$-Value of 0.032 which was less than the significance level of 0.05 , hence the conclusion that there 
was evidence to suggest, internet knowledge really had an influence on perceived security of E-marketing. However, the last Chi-Square test conducted showed that there was weak evidence to suggest that level of education had an influence on perceived security of E-Marketing. The $P$-value of 0.974 obtained was greater than the significance level of 0.05 , hence the test was insignificant and a conclusion that education had no influence on perceived security of E-marketing was reached.

In order to address the "How" question raised in the preamble, an E-Marketing system called Zamefa E-Commerce was developed in this research which Cable manufacturing companies could adopt to enhance their competitive advantage. This could help them reach their target markets irrespective of the regional and international boundaries. The Zamefa E-Commerce system was developed using open source tools or programs. An Open source tool or program is one which can be easily accessed on the internet by anyone and at no cost. The system was developed with Wamp Server, a software which allows the creation of a data base where key data and information could be kept. PHP software was also used to create a website and other web applications. Apache Web Server was utilized to allow hosting of one or more websites on the system.

The developed system works in such a way that it allows the manufacturing companies to interact with the prospective client by providing an interface where they can create their own accounts, have access to the product catalogue and select the preferred products to buy. Payments can also be made except it requires to have a link with agents that handle such i.e. pay pal. Unfortunately, the system developed does not go that far, but it can be improved further by another researcher. Furthermore, other unlimited facilities can be accessed on the Zamefa E-Commerce system such as real time conversation with clients, provisions where clients can send in enquiries, concerns, suggestions and other issues which could be directed straight to that company's help desk for immediate attention. Lastly, the Zamefa E-Commerce system developed can also allow a company to advertise its products to the target customers. The researcher therefore, argues that Zamefa E-Commerce is the most feasible system which can help cable manufacturing companies achieve their sales targets as they adopt E-Marketing. It is user friendly and leaves room for further development.

\subsection{Recommendations}

In order to encourage acceptance of technology, the research recommended that the users be adequately trained to gain more knowledge and exposure. Training could involve arranging seminars on the benefits and use of Technology, i.e. various application packages. It was observed that respondents who spent more time on their computers were more receptive to technology. Therefore, training could help them become familiar with technology and foster familiarization, which may ultimately lead to acceptance. Additionally, cable manufacturing companies should consider adopting an E-Marketing system like the one devel- 
oped in this research in order to take advantage of global markets and keep themselves at bay with ever changing customer tastes and preferences. Currently, only Zamefa has a website while the other two cables manufacturing have none.

\subsection{Limitations and Future Research}

Just like many others, this research had limitations too. In this study, only three cable manufacturers were considered yet there are other cables manufacturers that own manufacturing facilities outside Zambia but sell them to the Zambian market. Future researchers should consider taking account of these companies and compare results.

Lastly, future researchers should consider undertaking a study that explains how the identified factors in this study that hinder the adoption of E-Marketing really hinder it. This research only identified the factors but did not go a step further to explain "HOW" they hinder technology acceptance.

\section{Acknowledgements}

The authors wish to acknowledge all associates that assisted in this research.

\section{Conflicts of Interest}

The authors declare no conflicts of interest regarding the publication of this paper.

\section{References}

Ajzen, I. (1991). The Theory of Planned Behavior. Organizational Behavior and Human Decision Processes, 50, 179-211. https://doi.org/10.1016/0749-5978(91)90020-T

Ajzen, I., \& Fishbein, M. (1980). Understanding Attitudes and Predicting Social Behavior. Englewood Cliffs, NJ: Prentice-Hall.

Akrimi, Y., \& Khemakhem, R. (2012). What Drive Consumers to Spread the Word in Social Media? Journal of Marketing Research \& Case Studies, 2012. http://www.ibimapublishing.com/journals/JMRCS/jmrcs.html.

Andreki, P. H. A., \& Yazdanifard, R. (2014). Is E-Marketing the Future of Marketing Field? https://file.scirp.org/pdf/AJIBM_2014070910343740.pdf

Avciyucel, U., \& Gulbahar, Y. (2013). Technology Acceptance Model: A Review of the Prior Predictors. Journal of Faculty of Educational Sciences, 46, 89-109. https://doi.org/10.1501/Egifak_0000001275

Bandura, A. (1986). Social Foundations of Thought and Action: A Social Cognitive Theory. Englewood Cliffs, NJ: Prentice Hall.

Bolos, C., Idemudia, E. C., Mai, P., Rasinghani, M., \& Smith, S. (2016). Conceptual Models on the Effectiveness of E-Marketing Strategies in Engaging Consumers. Journal of International Technology and Information Management, 25, Article 3.

Dahiru, T. (2008). P-Value, a True Test of Statistical Significance? A Cautionary Note. Annals of Ibadan Postgraduate Medicine, 6, 21-26. https://www.ncbi.nlm.nih.gov/pmc/articles/PMC4111019

Daka, C. G., \& Phiri, J. (2019). Factors Driving the Adoption of E-Banking Services Based 
on the UTAUT Model. International Journal of Business and Management, 14, 43. https://doi.org/10.5539/ijbm.v14n6p43

Davis, F. D. (1989). Perceived Usefulness, Perceived Ease of Use, and User Acceptance of Information Technology. MIS Quarterly, 13, 319-339. https://doi.org/10.2307/249008

Ducass, A., \& Kwadjane, J. M. (2015). E-Commerce in Africa: Morocco, Tunisia, Senegal and Ivory Coast. Recommendations for Regional Integration in the Mediterranean.

Durodolu, O. (2016). Technology Acceptance Model as a Predictor of Using Information System to Acquire Information Literacy Skills. Library Philosophy and Practice, 1450. http://digitalcommons.unl.edu/libphilprac/1450

El-Gohary, H. (2014). E-Marketing-A Literature Review from a Small Businesses Perspective. International Journal of Business and Social Science, 1, 214. https://doi.org/10.4018/jcrmm.2010070105

Khan, M. (n.d.). The Use of E-Marketing for E-Ttractions.

Kotler, P., \& Armstrong, G. (2008). Principles of Marketing (12th ed.). London: Pearson Education Limited.

Mwiya, B., Chikumbi, F., Shikaputo, C., Kabala, E., Kaulung’ombe, B., \& Siachinji, B. (2017). Examining Factors Influencing E-Banking Adoption: Evidence from Bank Customers in Zambia. American Journal of Industrial and Business Management, 7, 741-759. https://doi.org/10.4236/ajibm.2017.76053

Olotewo, J. (2017). Examining the Antecedents of In-Store and Online Purchasing Behavior: A Case of Nigeria. Journal of Marketing Research and Case Studies, 2017. http://ibimapublishing.com/articles/JMRCS/2017/668316/

Onyeocha, A., \& Chinosa, L. (2015). The Impact of E-Marketing and Services: To Achieving Effective Customer's Service in the Hospitality Industry in Nigeria. Merit Research Journal of Business and Management, 3, 56-65. http://www.meritresearchjournals.org/bm/index.htm

Sahli, A. B. (2015). Revisiting Perceived Risk and Trust in E-tourism Context: Toward an Extended Technology Acceptance Model. Journal of Marketing Research and Case Studies, 2015. http://www.ibimapublishing.com/journals/JMRCS/jmrcs.html

Sakala, L., \& Phiri, J. (2019). Factors Affecting Adoption and Use of Mobile Banking Services in Zambia Based on TAM Model. Open Journal of Business and Management, 7, 1380-1394. https://doi.org/10.4236/ojbm.2019.73095

Sharma, R., \& Mishra, R. (2014). A Review of Evolution of Theories and Models of Technology Adoption. Indore Management Journal, 6, 17-29.

Soneka, P. N., \& Phiri, J. (2019). A Model for Improving E-Tax Systems Adoption in Rural Zambia Based on the TAM Model. Open Journal of Business and Management, 7, 908-918. https://doi.org/10.4236/ojbm.2019.72062

Venkatesh, V., Morris, M. G., Davis, G. B., \& Davis, F. D. (2003). User Acceptance of Information Technology: Toward a Unified View. MIS Quarterly, 27, 425-478. https://doi.org/10.2307/30036540 